JURNAL ILMIAH KOMPUTERISASI AKUNTANSI, Vol. 13, No. 1, Juli 2020, pp. 24 - 36

p-ISSN : 1979-116X (print)

e-ISSN : 2614-8870 (online)

http://journal.stekom.ac.id/index.php/kompak

\title{
SISTEM INFORMASI AKUNTANSI PENERIMAAN DAN PENGELUARAN KAS BERBASIS MULTIUSER DI SMK PATI UNUS KARANGAWEN DEMAK
}

\author{
Kasih Purwantini ${ }^{1}$, Danang Danang ${ }^{2}$, Siti Nasekah ${ }^{3}$ \\ ${ }^{1}$ Progdi Akuntansi - Universitas Sains \& Teknologi Komputer, ti pung@ymail.com \\ ${ }^{2}$ Progdi Teknik Elektro - Universitas Sains \& Teknologi Komputer, danang@stekom.ac.id \\ ${ }^{3}$ Progdi Komputer Akuntansi - Universitas Sains \& Teknologi Komputer, $\underline{\text { Siti@ymail.com }}$ \\ Jl. Majapahit 605, Semarang, telp/fax : 024-6717201-02
}

\section{ARTICLE INFO}

Article history:

Received 30 Mei 2020

Received in revised form 2 Juni 2020

Accepted 10 Juni 2020

Available online 26 Juni 2020

\begin{abstract}
This study designed a system that is able to assist companies in calculating cash receipts and disbursements. The Accounting Information System for Cash Receipts and Expenditures will be equipped with the use of user log-ins to maintain the level of data security so that not just anyone can misuse the data. The system designed will also be equipped with security of access rights and data storage systems, providing a database using the Visual Basic 6.0 programming language that holds records of cash receipts and disbursements to be a good report, summarizing the process of moving data from ledgers to becoming cash reports flow, and can document each period's report so that it can be grouped properly. The research method used is the Borg and Gall R\&D research approach which consists of 10 stages, out of 10 R\&D stages the author only conducts the research approach to the 6th stage alone. and monitoring cash flow very well. In addition, it can also produce reports that are precise, accurate and efficient.
\end{abstract}

Keywords: Information Systems, Cash Receipts and Expenditures, SQL Server 2000, Microsoft Visual Basic 6.0..

\section{Pendahuluan}

Perkembangan teknologi sangat mempengaruhi setiap bidang kehidupan manusia, salah satunya adalah teknologi informasi. Teknologi informasi menjadi sangat penting bagi kebutuhan saat ini, karena kebutuhan untuk memperoleh data dan informasi harus cepat dan efisien. Peranan keuangan sangat mempengaruhi suatu perusahaan atau instansi, sehingga laporan keuangan sangat penting dan perlu dikembangkan dan diciptakan suatusistem baikdalamsistem pencatatan, pengelolaan, maupun pengolahan data keuangan. Cash flow (aliran kas) merupakan sejumlah uang kas yang keluar dan yang masuk sebagai akibat dari aktivitas perusahaan. Arus kas masuk adalah arus kas yang terjadi dari kegiatan transaksi yang melahirkan keuntungan kas yang disebut penerimaan kas, sedangkan arus kas keluar adalah arus kas yang terjadi dari kegiatan transaksi yang mengakibatkan biaya pada kas yang disebut pengeluaran kas (Maruli, 2013).

Prosedur penerimaan kas dari pembayaran administrasi sekolah atas transaksi SPP dimulai dengan siswa datang ke bagian bendahara dengan menyerahkan kartu SPP dan uang pembayaran. Selanjutnya bendahara mencatat jenis pembayaran dan jumlah transaksi tersebut di kartu SPP dan buku penerimaan kas,

Received Mei 30, 2020; Revised Juni 10, 2020; Accepted Juni 26, 2020 
kartu SPP dikembalikan kepada siswa. Sedangkan penerimaan kas dari transaksi daftar ulang dan dana SPI dimulai dengan siswa datang ke bagian bendahara dan membayar biaya sesuai transaksi yang dimaksud. Penerimaan kas dari dana BOS dimulai proses pencairan dari dinas pendidikan ke rekening sekolah, setelah proses pencairan dana bos dari dinas pendidikan dilakukan, dengan segera rekening sekolah akan dicairkan oleh pihak sekolah

Prosedur pengeluaran kas untuk membiayai honor guru dan karyawan dimulai dari bagian tata usaha mencatat biaya yang harus dikeluarkan sesuai dengan absensi masing - masing guru dan karyawan dan diserahkan ke bagian bendahara, kemudian bagian bendahara merekapnya ke dalam buku pengeluaran kas. Selain transaksi honor guru dan karyawan pengeluaran kas juga terjadi dari transaksi lainnya seperti pembelian perlengkapan sekolah (buku,tinta printer, alat tulis), untuk transaksi tersebut bagian bendahara mencatat di buku pengeluaran kas dan mengumpulkan bukti transaksi. Setelah akhir bulan bagian bendahara melakukan input semua transaksi penerimaan dan pengeluaran kas ke dalam microsoft excel dari awal bulan sampai akhir bulan.

Dari uraian permasalahan dalam pengelolaan data keuangan yang ada serta mengingat pentingnya data keuangan bagi instansi maka diperlukan suatu sistem yang mampu mendukung proses pengolahan data sehingga menghasilkan laporan yang tersistem. Untuk itu penulis memberikan solusi pengelolaan keuangan dengan membuat Sistem Informasi Akuntansi Penerimaan dan Pengeluaran Kas di SMK Pati Unus Karangawen Demak dengan jaringan berbasis Multiuser dan menggunakan database SQL server 2000. Sistem ini dapat memberikan informasi mengenai keuangan sekolah secara benar, tepat dan cepat karena menghasilkan laporan keuangan secara otomatis. Sistem informasi ini dirancang dengan sistem informasi berbasis multiuser sehingga memungkinkan pengguna lebih dari satu dalam mengakses sistem komputer dalam waktu yang bersamaan. Sistem Informasi Akuntansi Penerimaan dan Pengeluaran Kas ini akan dilengkapi dengan penggunaan log-in user untuk menjaga tingkat keamanan data sehingga tidak sembarang orang bisa menyalahgunakan data. Sistem yang dirancang juga akan dilengkapi dengan keamanan sistem hak akses dan penyimpanan data,menyediakan suatu database penyimpanan yang menampung pencatatan penerimaan dan pengeluaran kas hingga menjadi suatu laporan yang baik, meringkas proses pemindahan data dari buku besar hingga menjadi laporan cash flow, dan dapat mendokumentasikan laporan tiap periode agar dapat dikelompokkan dengan baik. Dengan demikian sistem informasi yang hendak dibangun ini diharapkan dapat membantu meningkatkan kinerja setiap bagian dan efisiensi instansi

\section{Perumusan Masalah}

1. Berdasarkan latar belakang masalah yang telah diuraikan maka penulis merumuskan masalah sebagai berikut Bagaimana merancang suatu sistem informasipenerimaan dan pengeluaran kas berbasis multiuser yang dapat melakukan proses pencatatan data akun kas secara otomatis dari buku besar sampai ke laporan cash flow?

2. Bagaimana membuat sistem informasi penerimaan dan pengeluaran kas berbasis multiuser yang mempunyai sistem hak akses yang hanya bisa diakses oleh pihak yang berkepentingan?

3. Bagaimana membuat produk sistem informasi akuntansi penerimaan dan pengeluaran kas berbasis multiuser agar laporan dapat terdokumentasikan dengan baik per periode?

\section{Landasan Teori}

\section{Akuntansi}

Akuntansi adalah suatu proses mencatat, mengklarifikasi, meringkas, mengolah dan menyajikan data, transaksi serta kejadian yang berhubungan dengan keuangan sehingga dapat digunakan oleh orang yang menggunakannya dengan mudah dimengerti untuk pengambilan suatu keputusan serta tujuan lainnya. Akuntansi merupakan sistem informasi yang memberikan laporan kepada pihak pihak yang berkepentingan mengenai kegiatan ekonomi dan kondisi perusahaan(Ferra, 2015).

\section{Kas}

Kas adalah alat pembayaran yang dimiliki perusahaan dan siap digunakan untuk investasi maupun menjalankan operasi perusahaan setiap saat dibutuhkan (Ikit, 2015).

\section{Arus Kas}


Laporan Arus Kas adalah suatu laporan tentang aktivitas penerimaan dan pengeluaran kas perusahaan selama suatu periode tertentu, beserta penjelasan tentang sumber - sumber penerimaan dan pengeluaran kas tersebut (Ikit, 2015).

\section{Pengertian Sekolah}

Sekolah atau lembaga pendidikan secara umum merupakan miniatur masyarakat (mini society) oleh sebab itu daur kehidupan sebagaimana yang terjadi pada kehidupan yang nyata juga berlangsung di sekolah. Meski demikian, secara lebih rinci sekolah merupakan wahana pengembangan peserta didik dimana proses di dalamnya adalah proses pelayanan jasa (Ketut, 2015).

\section{$R \& D$}

Metode penelitian dan pengembangan $(R \& D)$ merupakan metode penilitian yang digunakan apabila peneliti bermaksud meghasilkan produk tertentu, dan sekaligus menguji keefektifan produk tersebut. Dengan metode R\&D diharapkan dapat ditemukan dan diuji produk-produk baru yang berguna bagi kehidupan manusia, lembaga dan masyarakat. Tujuan pertama disebut sebagai fungsi pengemban sedangkan tujuan kedua disebut sebagai validasi. Dengan demikian, konsep penelitian pengembangan lebih tepat diartikan sebagai upaya pengembangan yang sekaligus disertai dengan upaya validasinya(Sugiyono, 2011).

\section{Pengertian Microsoft Visual Basic 6.0}

Visual Basic merupakan sebuah bahasa pemrograman yang menawarkan Integrated Development Environtmen (IDE) visual untuk membuat program perangkat lunak berbasis operasi Microsoft Windows menggunakan model pemrograman (COM) (Stefano, 2014).

\section{SQL Server 2000}

$S Q L$ Server 2000merupakan salah satu produk microsoft yang cukup powerful. SQL Server 2000 memiliki banyak fitur yang membantu para pengembang aplikasi database untuk membangun aplikasi dalam skala yang besar. SQL Server 2000 mengimplementasi konsep database relasional. Database relasional adalah database yang mengorganisasikan data dalam bentuk tabel (Fauzi dan M. Miftakul Amin, 2012).

\section{Metodologi}

Metodologi penelitian adalah metode yang akan digunakan dalam melakukan penelitian. Dalam penyusunan skripsi ini akan digunakan metode sebagai berikut:

a. Obyek Penelitian

Yang menjadi tempat penelitian ini adalah arus kas SMK Pati Unus Karangawen Demak di Jalan Raya Karangawen Km. 19,5 Rt 01 Rw 08 Kecamatan Karangawen Kabupaten Demak,

Jenis Data

Berdasarkan sumber data yang diperoleh, maka jenis data dapat menggunakan dua sumber dara yaitu :

1. Data Primer adalah data yang diperoleh dari penelitian secara langsung terhadap objek penelitian yaitu memasukkan data pembayaran siswa di sekolah SMK Pati Unus di Jalan Raya Karangawen Km. 19,5 Rt 01 Rw 08 Kecamatan Karangawen Kabupaten Demak

2. Data Sekunder adalah data yang terlebih dahulu dikumpulkan dan dilaporkan oleh orang, dari literatur perusahaan atau yang diperoleh dari perpustakaan berupa pengertian dan konsep dan definisi-definisi, meliputi kegiatan perusahaan, struktur organisasi perusahaan.

b. Metode pengumpulan data

Dalam pembuatan proposal ini perlu dilakukan suatu usaha pengumpulan data, dan data tersebut yang akan digunakan sebagai alat untuk memecahkan masalah yang ada didalamnya. Untuk itu diperlukan beberapa metode yang diperlukan dalam pengumpulan data tersebut, yaitu:

1. Pengamatan (observasi)

3. Untuk hal ini penulis mengadakan pengamatan langsung mengenai pemasukan dan pegeluaran di SMK Pati Unus Jalan Raya Karangawen Km. 19,5 Rt 01 Rw 08 Kecamatan Karangawen Kabupaten Demak

2. Wawancara (interview)

Untuk hal ini penulis melakukan pencarian data melalui Tanya jawab di SMK Pati Unus Jalan Raya Karangawen Km. 19,5 Rt 01 Rw 08 Kecamatan Karangawen Kabupaten Demak seperti sistem pencatatan penerimaan dan pengeluaran kas hingga menjadi suatu laporan, meringkas proses pemindahan data dari buku besar hingga menjadi laporan cash flow.

Studi kepustakaan 
Studi kepustakaan dilakukan untuk mendapatkan data agar permasalahan dapat diselesaikan secara teoritis, menunjang data-data yang telah diperoleh dari metode lapangan serta menguatkan pendapat dalam menganalisa hasil penelitian lapangan sehingga permasalahan yang ada dapat diselesaikan dengan baik.

3. Metode pengembangan sistem

Metode yang digunakan adalah prototyping yaitu satu versi dari sebuah sistem potensial yang memberikan ide bagi para pengembang dan calon pengguna, bagaimana sistem akan berfungsi dalam bentuk yang telah selesai.

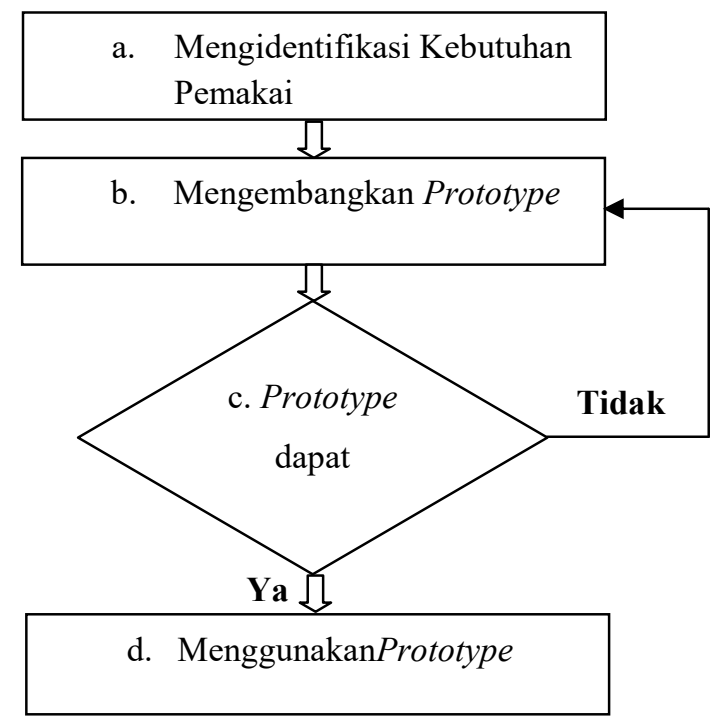

Gambar 1 Pembuatan prototyping evolusioner

(Yulia dan Dewi, 2015)

4. Mengindetifikasi kebutuhan pengguna

Mengumpulkan masalah-masalah yang terjadi di SMK Pati Unus Jalan Raya Karangawen Km. 19,5 Rt 01 Rw 08 Kecamatan Karangawen Kabupaten Demak tentang Sistem penerimaan dan pengeluaran kas hingga menjadi suatu laporan, meringkas proses pemindahan data dari buku besar hingga menjadi laporan cash flow.

5. Membuat sebuah prototyping

Menyiapkan rancangan Flowchart, DFD, Normalisasi, ERD, Visual Basic 6.0, User Interface (Form), database SQL Server.

6. Persetujuan pengguna

Setelah materi terkumpul semua tahapan selanjutnya adalah Perancangan Sistem Informasi Akuntansi Penerimaan dan Pengeluaran Kas dengan membuat desain aplikasi yang berisi : Flowchart, DFD, Normalisasi, ERD, Visual Basic 6.0, User Interface (Form), database SQL Server , dan pembuatan kode aplikasi.

7. Mengunakan prototyping

Perancangan Sistem Informasi Akuntansi Penerimaan dan Pengeluaran Kas, tapi apabila valid program dapat digunakan sebagai produk prototype sistem informasi yang nanti dapat di implementasikan kepada user yaitu bendahara, bagian staf tata usaha dan kepala sekolah dengan penambahan hak akses user untuk pembatasan pemakai sistem informasi. Setelah melalui tahap uji coba dan hasilnya baik maka prototyping siap digunakan oleh user.

\subsection{Bahan Penelitian}

a. Hardware antara lain :

1) 2 unit komputer.

$$
\begin{array}{ll}
\text { Processor } & : \text { Intel Core 1017U. } \\
\text { Memory } & : 4 \mathrm{~GB} . \\
\text { Hardisk } & : 500 \mathrm{~GB} .
\end{array}
$$


Monitor : 14 Inc.

2) 1 unit Printer.

3) Mouse 3D Optimal.

b. Software antara lain :

1) Sistem operasi Microsoft Windows 7.

2) Desain produk menggunakanMicrosoft Visual Basic 6.0.

3) Database menggunakan SQL Server 2000.

Form yang dibutuhkan aplikasi ini adalah sebagai berikut :

1. Input Data terdiri dari :
a. Form Log in administrasi.
b. Form Hak Akses.
c. Form Data Siswa.
d. Form Data Pegawai.
e. Form Input Data Akun.

2. Proses Transaksi Antara lain :
a. Form Pembayaran SPP.
b. Form Transaksi Penerimaan Kas.
c. Form Transaksi Pengeluaran Kas.

3. Output Data Laporan terdiri dari :
a. Form Laporan Data Siswa
b. Form Laporan Data Pegawai
c. Form Laporan Pembayaran SPP.
d. Form Laporan Penerimaan Kas.
e. Form Laporan Pengeluaran Kas.
f. Form Laporan Jurnal Umum.
g. Form Laporan Buku Besar.
h. Form Laporan Cash Flow.

4. Pembagian Hak Akses Pemakai.

a. Bendahara Tata Usaha : Mempunyai hak akses menginput data Pembayaran SPP, Penerimaan Kas dan Pengeluaran Kas, serta mencetak laporan.

b. Staff Tata Usaha : Mempunyai hak akses menginput data siswa, data pegawai dan melakukan evaluasi laporan.

c. Kepala Sekolah:Mempunyai hak akses melihat dan menerima laporan.

\subsection{Desain Penelitian \\ Context Diagram}




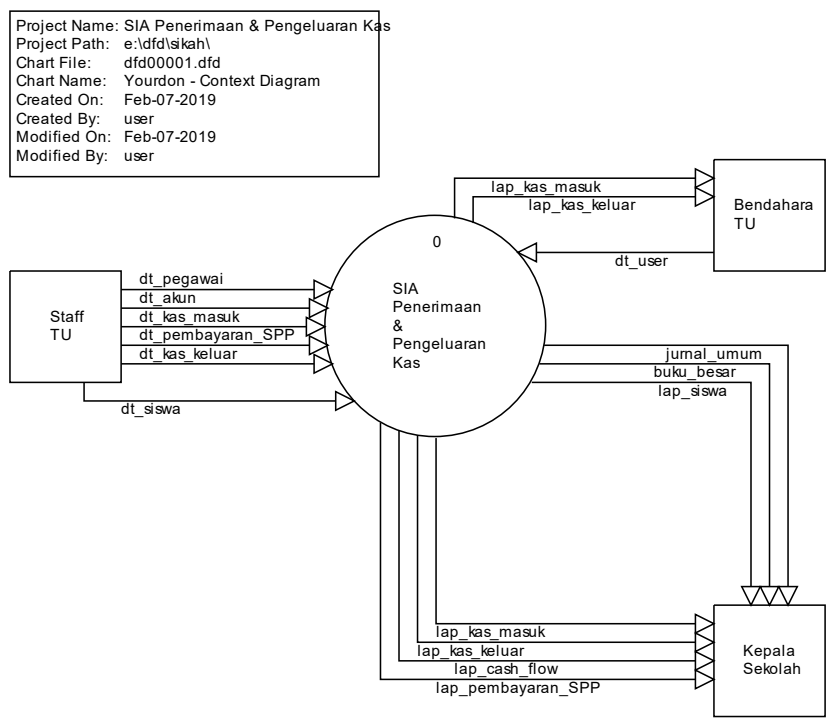

Gambar 2 Context Diagram

Data akun, siswa, pegawai, data pembayaran SPP, data kas masuk dan data kas keluar didapatkan dari Staff Tata Usaha. Bendahara menyusun daftar user yang bisa akses ke aplikasi dan menerima laporan data penerimaan dan pengeluaran kas untuk divalidasi. Keluaran yang dihasilkan dari system ini yang berupa laporan yang dibutuhkan oleh Kepala Sekolah.

Berikut merupakan DFD Level 0

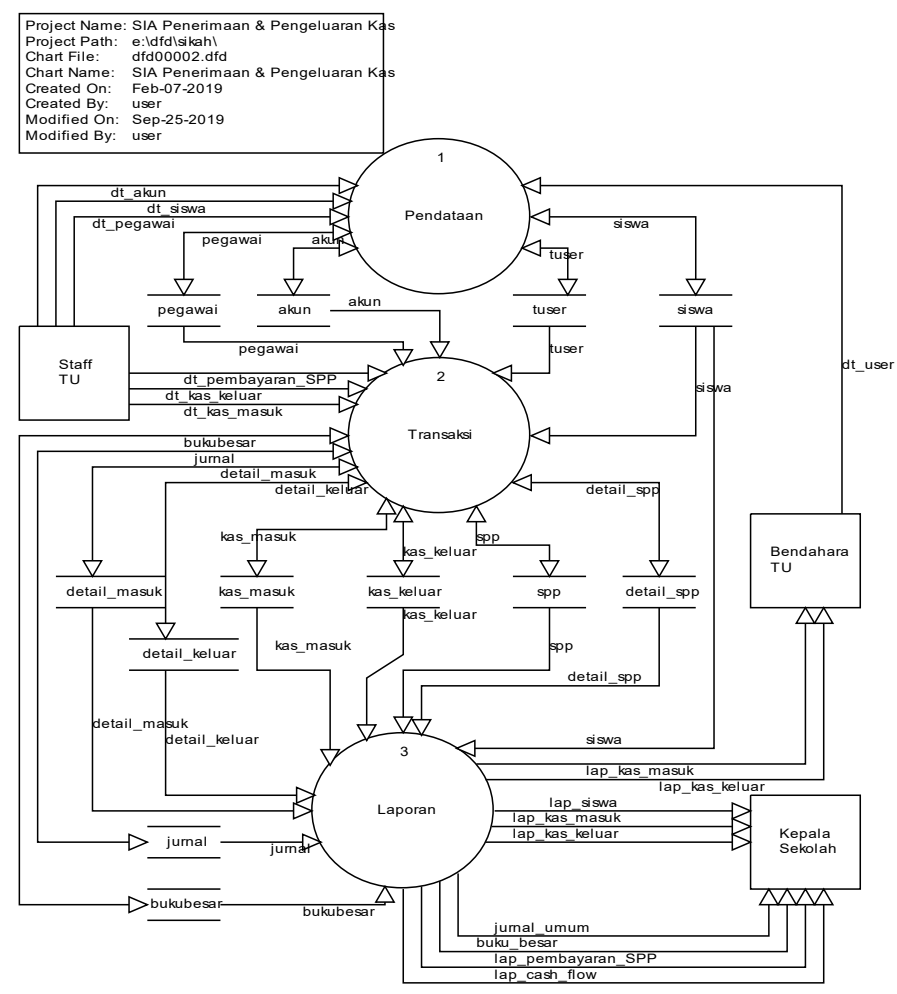

Gambar 3 DFD Level 0

menerangkan pembagian proses sistem menjadi 3 bagian, yaitu pendataan, transaksi dan laporan. Proses pendataan dan transaksi menghasilkan tabel-tabel yang diolah menjadi laporan. 
DFD Level 1 Transaksi



Gambar 4 Level 1 Transaksi

Pada transaksi terbagi menjadi 2 proses yaitu kas masuk, ka keluar dan pembayaran SPP yang masing-masing tersimpan dalam table kas_masuk, detail_masuk, kas_keluar, detail_keluar, spp, detail_spp, jurnal dan buku besar.

\subsection{Perancangan}

Membuat perancangan dimana langkah-langkahnya adalah :

1) Menentukan tujuan sistem

2) Membuat spesifikasi produk

3) Menyusun gambaran sistem rancangan program berupa Basis Data, Normalisasi, Diagram Konteks, Flowchart, DFD, ERD dan perancangan database serta perancangan user interface form-form tampilan yang akan dipergunakan dalam aplikasi tersebut. Membuat program, yaitu dengan pembuatan source code dengan menggunakan bahasa pemrograman Visual Basic 6.0.

\section{Hasil dan Pembahasan}

\section{Form Login}

Fungsi : Untuk pengamanan aplikasi dengan pembagian hak akses

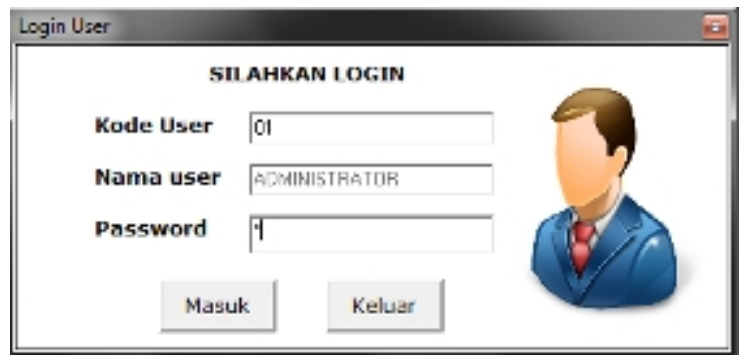

Gambar 5 Form Login

\section{Form Menu Utama}

Fungsi : Untuk Mempermudah User dalam membuka Form Master, Transaksi dan Laporan-laporan. 
31

JURNAL ILMIAH KOMPUTERISASI AKUNTANSI p-ISSN : 1979-116X e-ISSN : 2614-8870 •

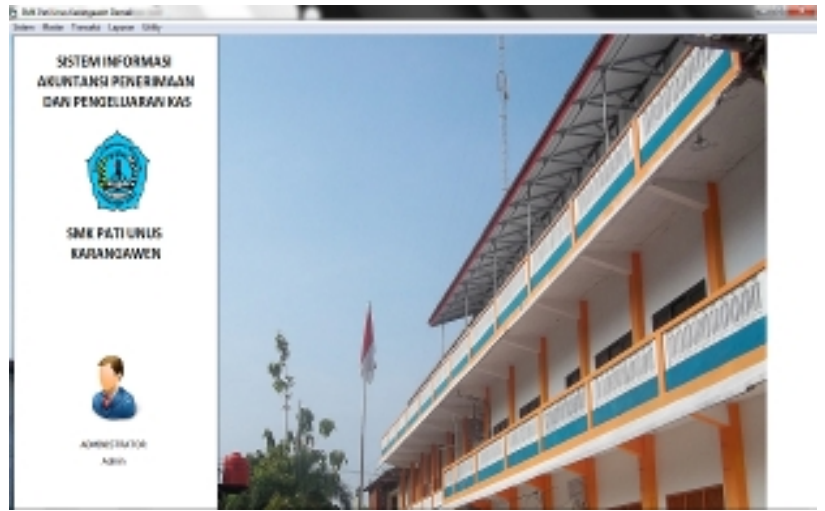

Gambar 6 Form Menu Utama

\section{Form Siswa}

Untuk menginput nama siswa dari masing - masing kelas dan jurusan.

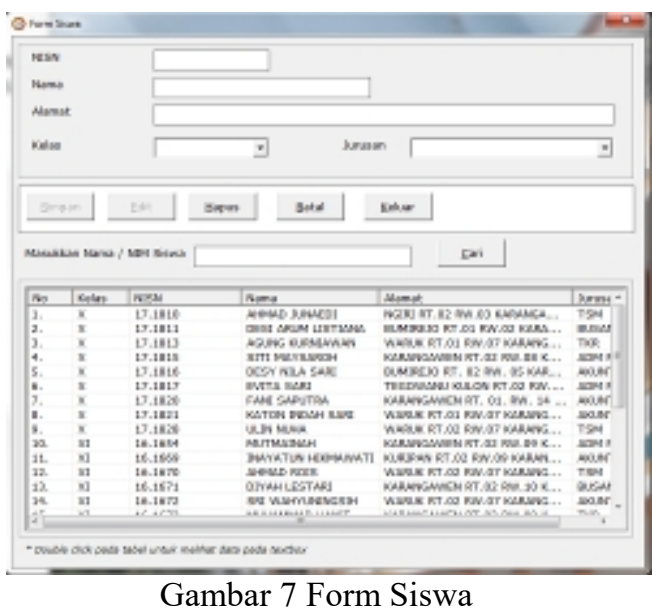

\section{Form Kode Akun}

Untuk menginput kode akun dari masing - masing kategori. User yang dapat mengakses form ini adalah bendahara sekolah.

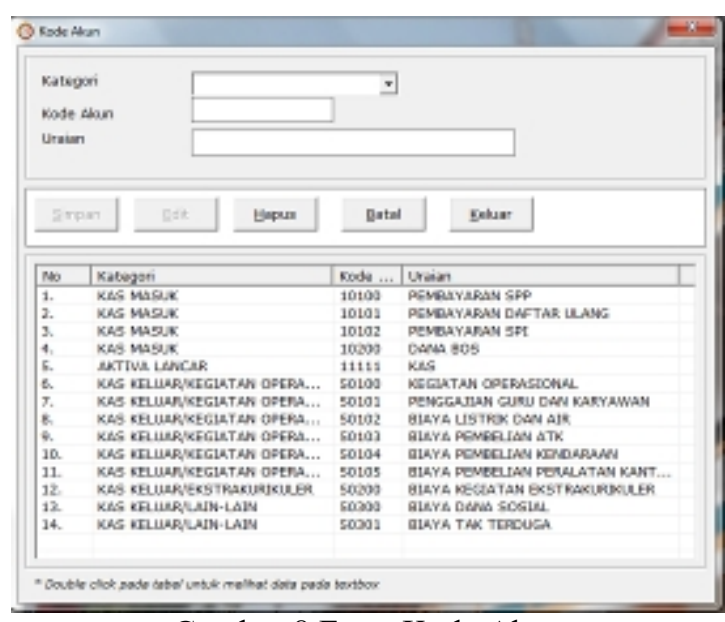

Gambar 8 Form Kode Akun 


\section{Form Pembayaran SPP}

Sebagai input transaksi data pembayaran SPP. Useryang dapat mengakses form ini adalah bendahara sekolah.

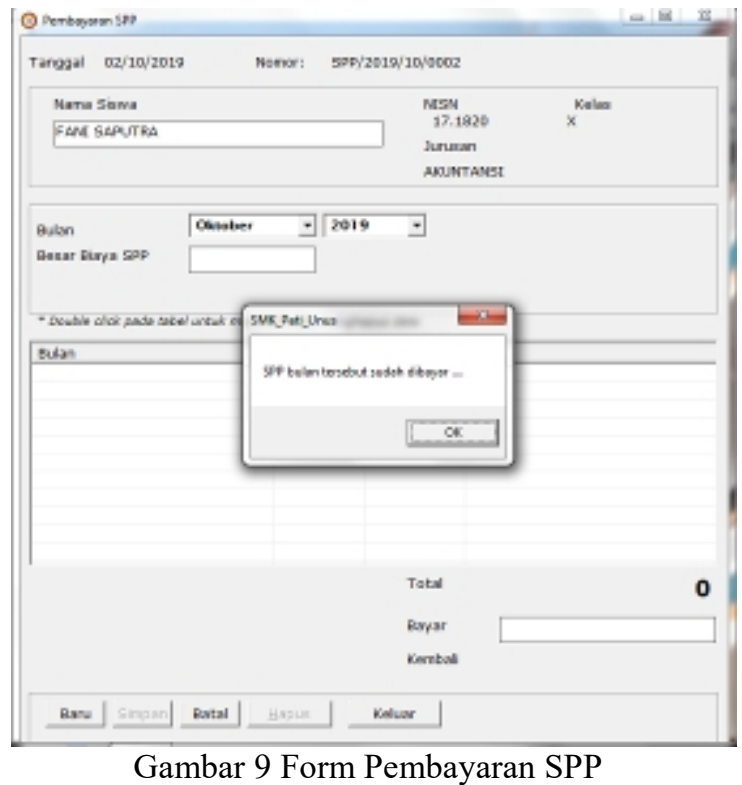

\section{Form Penerimaan kas}

Sebagai input transaksi data penerimaan kas. User yang dapat mengakses form ini adalah bendahara sekolah.

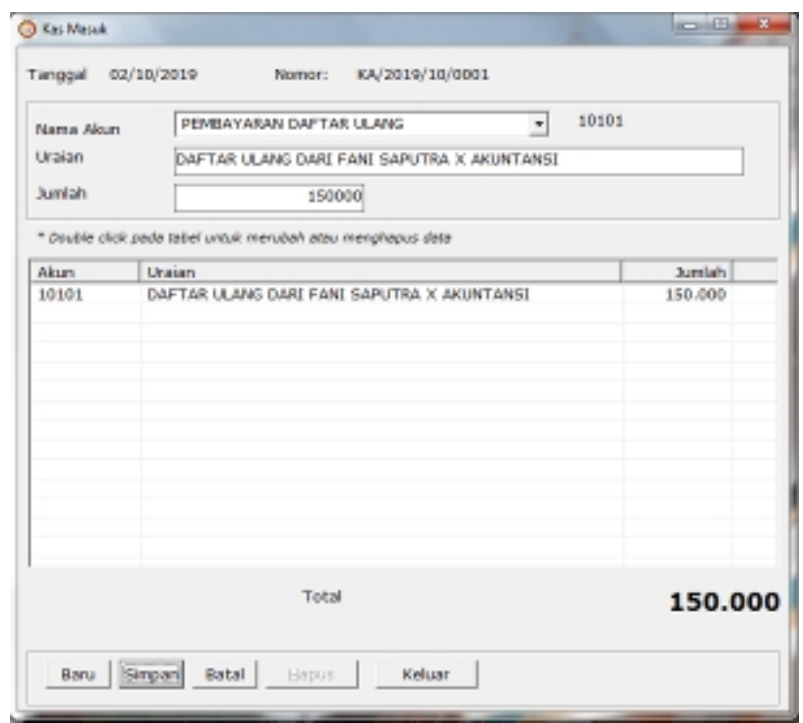




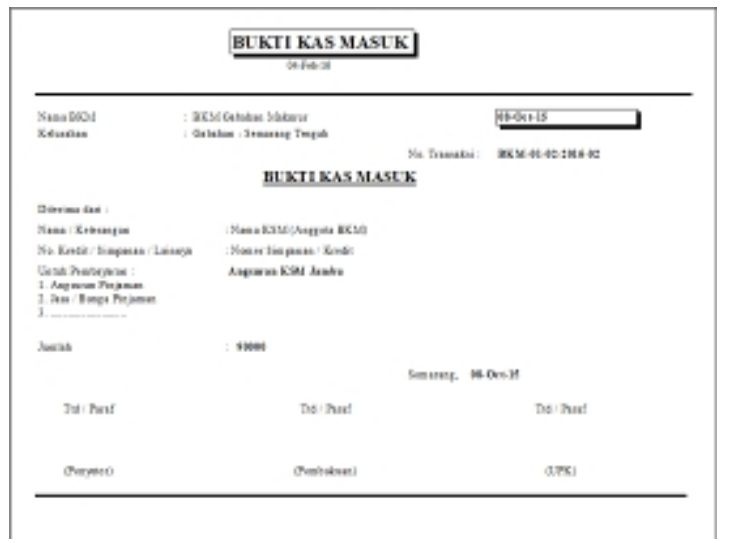

Gambar 10 Form Penerimaan kas

\section{Form Pengeluaran Kas}

Sebagai input transaksi data pengeluaran kas. User yang dapat mengakses form ini adalah bendahara sekolah


8.Form Laporan jurnal

Untuk input tanggal transaksi dan melihatnya sebagai laporan jurnal umum 
34

JURNAL ILMIAH KOMPUTERISASI AKUNTANSI p-ISSN : 1979-116X e-ISSN : 2614-8870 •

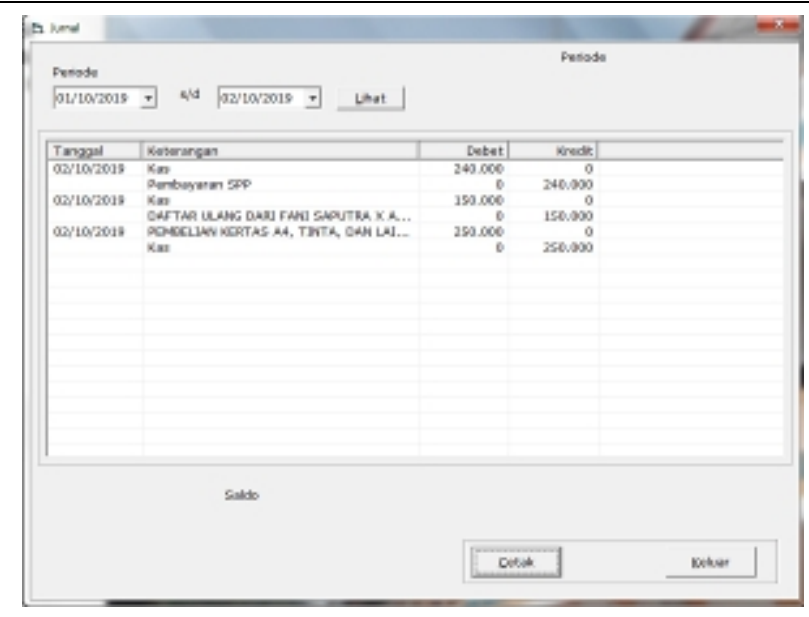

Gambar 12 Form Laporan jurnal

9.Laporan Buku Besar

Untuk input tanggal transaksi dan melihatnya sebagai laporan Buku Besar.

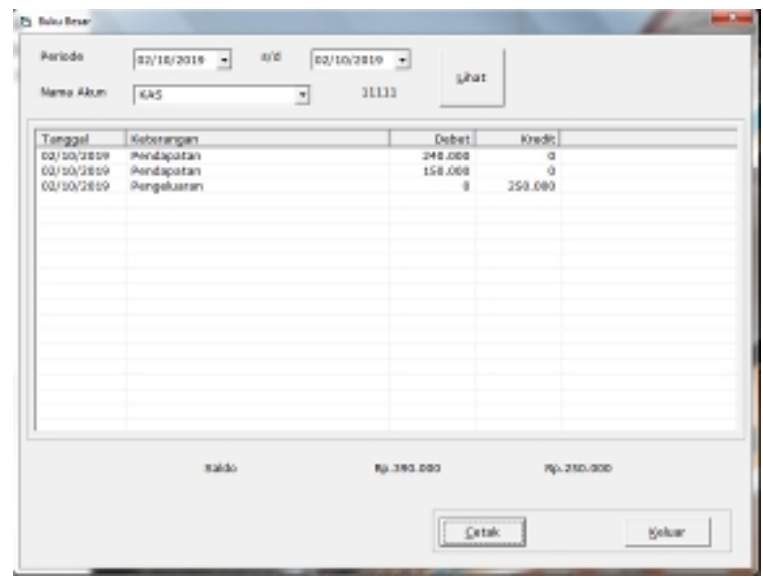

Gambar 13 Laporan Buku Besar

10. Form Aktifitas Keuangan (Cash Flow)

Untuk input tanggal transaksi dan melihatnya sebagai laporan Cash Flow.

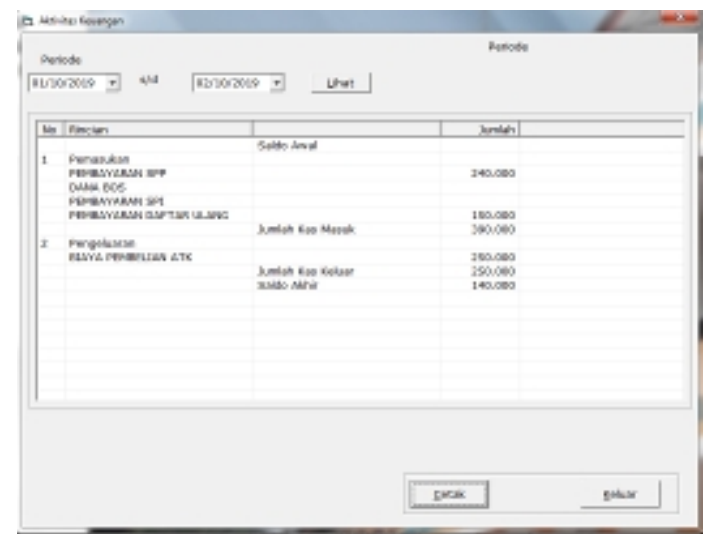

Gambar 14 LaporanCash Flow 
11. Laporan Data Siswa



Gambar 15 Laporan Data Siswa

12. Laporan Pembayaran SPP

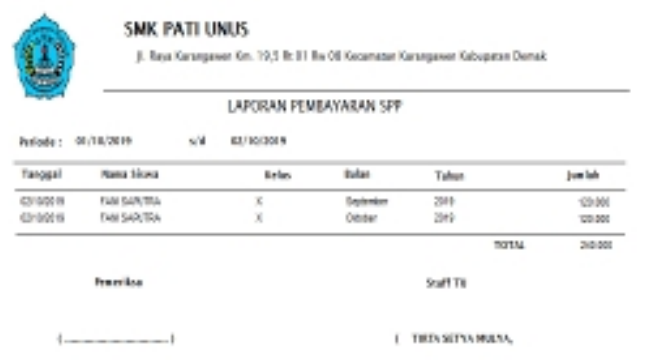

Gambar 16 Laporan Pembayaran SPP

13. Laporan Cash Flow

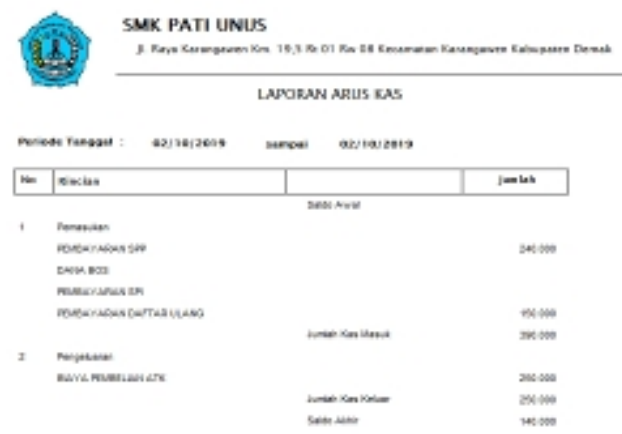

Gambar 17 laporan Cash Flow

\section{Kesimpulan}

Adanya uji coba validasi yang dilakukan oleh pakar internal dan pemakai (user) dapat membantu produk yang dibuat penulis menjadi lebih baik dengan saran - saran perbaikan yang diberikan Adanya sistem informasi penerimaan dan pengeluaran kas yang terkomputerisasi, user lebih mudah melakukan kegiatan pencatatan transaksi penerimaan kas dan pengeluaran kas karena seluruh transaksi tersimpan 
dan terhubung dalam satu database serta dilengkapi dengan keamanan hak akses untuk beberapa user yang berkepentingan menggunakan sistem ini. Sistem informasi penerimaan dan pengeluaran kas yang diusulkan, maka penyajian laporan kas dapat menjadi lebih cepat sehingga dapat meminimalisir waktu pencatatan dan kesalahan pencatatan, dan adanya sistem informasi penerimaan dan pengeluaran kas, pengguna akan lebih mudah dalam melakukan pencetakan laporan kas dengan hasil yang akurat.

\section{Daftar Pustaka}

Borg, Walter R , \& Gall, M.D, 1983 ; “ Educational research: An introduction (4ed) “, New York \& London : Longman. Bunafit Nugroho dan Indah Indriyana, 2007; "Membuat Aplikasi Database SQL Server dengan Visual Basic 6.0”, Yogyakarta : Gava Media,.

Fauzi dan Amin, Miftakul H, 2012; "Pemrograman Database Visual Basic dan SQL Server 2000", Yogyakarta : CV. Andi Offset.

Ferra Pujiyanti, 2015; "Rahasia Cepat Menguasai Laporan Keuangan Khusus Dengan Akuntansi Dasar: Cara Tercepat dan Terbaik Untuk Menguasai Laporan Keuangan”, Jakarta : Lembar Langit Indonesia.

Ikit, 2015; “Akuntansi Penghimpun Dana Bank Syariah”, Yogyakarta : Deepublish.

Ketut Jelantik A.A., 2015; “Menjadi Kepala Sekolah yang Profesional ”, Yogyakarta : Deepublish.

Stefano, 2014; "Cara Membangun Sistem Informasi Menggunakan VB.Net dan Komponen Dxperience”, Yogyakarta : CV. Andi Offset.

Sugiyono,2011; “Metode Penelitian Kuantitatif kualitatif dan R\&D”, Bandung: Alfabeta. 